\title{
Controlled acute trial of a thyrotrophin releasing hormone analogue (RX77368) in motor neuron disease
}

\author{
R J GUILOFF, D J A ECKLAND, C DEMAINE, R C HOARE, K D MACRAE, \\ S L LIGHTMAN \\ From the Department of Neurology and Medicine, Charing Cross and Westminster Medical School, \\ Westminster Hospital, London, UK
}

SUMMARY Twenty five patients with motor neuron disease completed a double blind randomised cross over trial of RX77368, a stabilised TRH analogue, iv over 2 hours against saline. Temporary improvement in bulbar symptoms including speech, respiratory parameters, tongue movements and swallowing were seen. Fasciculations increased and spasticity decreased. Change in muscle force with drug was different from placebo but both increase and decrease in force were seen and did not result in detectable changes in function. Side effects were clinically significant in $50 \%$ of the patients and cleared within 12 hours. Prolonged rise of thyroxine and an increase in plasma levels of prolactin, thyroid stimulating hormone and growth hormone were seen and followed characteristic patterns.

Adult sporadic motor neuron disease has an incidence of about $1-1 \cdot 5 / 100000^{1}$ which is of the same order of magnitude as that of multiple sclerosis. ${ }^{2}$ Its prevalence, however, is much less than that of multiple sclerosis because about $75 \%$ of the patients die within 5 years of onset, usually from complications related to weakness in bulbar muscles. ${ }^{3}$

Since the initial report of a temporary effect of high dose intravenous thyrotrophin releasing hormone (TRH) on weakness and spasticity in patients with motor neuron disease, ${ }^{4}$ other groups in the USA, Japan, France and Germany have either confirmed some of the findings ${ }^{5-1277}$ or failed to do so. ${ }^{13-16}$ It has been suggested that longer acting TRH analogues with a higher benefit/side effect ratio might be tried in motor neuron disease ${ }^{4}$ but no controlled study has been published so far on their actions in this disease.

L-pyroglutamyl-L-hystidyl-L-3,3 dimethyl prolineamide (RX77368), a stabilised analogue containing a 3,3 dimethyl substituted prolineamide residue $e^{1718}$ which impairs degradation by peptidases, ${ }^{19}$ is $14-200$ times more potent than TRH on

Address for reprint requests: Dr RJ Guiloff, Westminster Hospital, Dean Ryle Street, Horseferry Road, London SWIP 2AP, UK.

Received 16 September 1986 and in revised form 22 December 1986. Accepted 5 January 1987 a molar basis on various tests of neuropharmacological activity, yet its endocrine effect is of the same magnitude. ${ }^{2021}$ Its systemic availability is four times more than that of TRH and its much greater neuropharmacological potency possibly relates to slow enzymatic degradation in nervous tissue, ${ }^{18192223}$ In humans plasma half life is 1080 minutes and half life in homogenates of brain tissue is 168 minutes, compared with 5-33 minutes and 18 minutes respectively for TRH. ${ }^{19} 20$ There is evidence to suggest an action of $\mathrm{RX77368}$ on rat motorneurons. 2425

We have studied the acute effects of RX77368 in consecutive motor neuron disease patients using a double blind, randomised, crossover design after an initial pilot study. Preliminary reports of this work have appeared elsewhere. ${ }^{26-29}$

\section{Patients, material and methods}

Two normal male volunteers aged 30 and 32 years and twenty eight patients participated; fourteen were male and fourteen female. Mean age of the twenty six patients that entered the controlled trial was 59.2 years (range 41 to 81 ) and their median duration of illness was 20.5 months (range 6-108). Mean age for males was 55.6 years (range 41-71) and for females $62 \cdot 8$ years (range $52-81$ ). Median time to severe incapacity was 13.5 months (range 5-54). All gave informed consent. The protocol was approved by the local Ethical Committee. All patients were in good general medi- 
cal condition and not neurologically terminal. RX77368 was provided by Reckitt and Colman, Pharmaceutical Division, Hull, UK.

Diagnostic criteria (a) Amyotrophic Lateral Sclerosis (ALS): simultaneous occurrence of upper and lower motor neuron signs in one or more limbs $(n=16)$. (b) Progressive Muscular Atrophy (PMA): lower motor neuron signs in one or more limbs $(n=4)$. (c) Progressive Bulbar Palsy (PBP): Flaccid and/or spastic paralysis of bulbar muscles with or without pyramidal signs in the limbs $(n=8)$. Bulbar signs were mild in one and prominent in four cases classified as ALS. They are grouped below as "bulbar syndrome" $(n=13)$ for analysis of drug effects. (d) Mixed forms: other combinations of the above were labelled in this report by the forms at onset or the predominant signs. (e) A progressive clinical course. (f) Normal cerebrospinal fluid. A rise in protein up to $1.6 \mathrm{~g} / 1$ can occur ${ }^{3}$ and was accepted. (g) Electromyographic evidence of denervation, including fasciculations in upper or lower limbs (preferably both). No reduction in maximal motor conduction velocity beyond what would be expected by the degree of wasting. Normal sensory conduction (particularly in mixed nerves with evidence of denervation in their motor distribution) except where coincidental entrapment neuropathy can be demonstrated. (h) Normal myelography in cases where it was judged clinically indicated.

All patients had weakness in the upper limbs. Four patients with PBP and one with ALS and prominent bulbar signs did not have weakness in the lower limbs. Onset of disease was obtained on careful questioning. Severe incapacity ( 17 cases) was defined as the presence of one or more of the following: unintelligible or nearly unintelligible speech and/or very impaired swallowing with easy choking or aspiration and inability to cough $(n=6)$, seriously impaired walking (less than 100 yards, frame or wheel chair required) $(n=8)$, inability to manipulate objects usefully with the dominant upper limb $(n=1)$, inability to perform activities of daily living unaided (feeding, bathing, toileting, dressing) $(\mathrm{n}=2)$. Mean Norris scale score ${ }^{30}$ was 65.5 (range 36-85).

\section{Assessments}

All patients had a full general medical examination including haematological, renal, hepatic, cardiovascular and endocrine investigation. Neurological examination included detailed assessment of muscle force both with the Medical Research Council scale ${ }^{31}$ and with a hand held dynamometer (Penny and Giles Transducers Ltd, Dorset, UK). ${ }^{32}$ Twenty one muscle groups were assessed with the latter in the controlled study, by the same examiner, in standard positions for force testing in each patient. They included neck flexion, right and left shoulder abduction, elbow extension and flexion, wrist extension, finger extension, index finger abduction, thumb abduction, hip flexion, knee extension and foot dorsiflexion. Maximal voluntary isometric contraction (MVC) was defined as the highest force after three satisfactory trials with adequate auditory stimulation ${ }^{32}$ which were all recorded. Spasticity was scored clinically $(0$ nil, 1 slight, 2 moderate, 3 severe). Fasciculations were deemed unchanged, decreased or increased by observation. Vital capacity (VC) and Peak flow (PF) were measured with a portable electronic spirometer. ${ }^{33}$ Maximal inspiratory and expiratory pressures (MIP, MEP) were measured with a specially designed instrument ${ }^{3435}$ containing pressure gauges BS1780. All neurological assessments were made by the same neurologist. Tape recordings of a standard piece of reading (100 words) were later scored blindly by one senior speech therapist using phonemic analysis. ${ }^{36}$ Swallowing was scored by observation and palpation in a scale from 0 (none) to 5 (normal). Lateral and vertical tongue movements were scored for range of movement (0-5). Palatal movement was scored for sustained elevation during 5 seconds (number of seconds and quality) and for five successive elevations (number and completeness of elevation). Scoring of repetition of a word with labial consonants was used to assess lip movement. The Norris scale ${ }^{30}$ score was computed. Walking a standard distance of 6 meters was timed. Electrophysiological measurements were carried out with a Neuromatic 2000M machine (Dantec). Dantec 13L20 disposable surface electrodes on abductor digiti minimi (ADM) and a Dantec 13L22 nerve stimulator were used. In decremental studies the amplitude of the negative peak of the 4th response is compared to the first response, at $3 \mathrm{~Hz}$. The temperature of the limb examined was monitored throughout and ranged from 31 to $33^{\circ} \mathrm{C}$. Pulse and blood pressure were monitored using a Sentron Automatic Blood Pressure Monitor (Bard Biomedical).

Radioimmunoassays of thyroxine $\left(\mathrm{T}_{4}\right)$, tri-iodothyronine $\left(\mathrm{T}_{3}\right)$, thyroid stimulating hormone (TSH), prolactin (PRL), growth hormone $(\mathrm{GH})$ and cortisol were all performed in the endocrine laboratory at Westminster Hospital.

\section{Procedure}

All patients were admitted to hospital. The two normal vol unteers received doses ranging from $25 \cdot 5 \mu \mathrm{g}$ to $1730 \mu \mathrm{g}$. It the open pilot study five patients were given intravenous infusions of RX77368 in doses ranging from $0.10 \mathrm{mg} / \mathrm{kg}$ to $1 \mathrm{mg} / \mathrm{kg}$ over 100 to 199 minutes. Twenty-six patients entered the double blind, placebo controlled, randomise $\bar{\Phi}$ crossover trial; three of them had taken part in the pilor study. MVC, VC, PF, MIP and MEP were measured daily for the first 5 days and also five times over 24 hours mimicking recordings during infusions. For respiratory parameters measurements over 24 hours were used as a baseline (fig 2, table 1). On days 5 and $12,300 \mu \mathrm{g} / \mathrm{kg}$ of RX77368 over 2 hours or saline were given in random order. Patients were fasted for 9 hours prior to the infusions. Measurements of MVC and respiratory parameters were performed immediately before infusion, at 1 hour, at the end of it and again 5-7 hours and 24 hours after it. Spasticity and fasciculations were scored before, at the end of, and up to 24 hours after infusion. Assessment of speech and other bulbar mediated functions was performed for each infusion at least three times; before, at the end and 4-8 hours after it. Walking was timed before and at the end of the infusions. Blood pressure and skin temperature were monitored throughout the infusions.

\section{Analysis of data and statistical methods}

Large fluctuations in force are seen in normals and in patients with neuromuscular disorders (fig 1). ${ }^{3237}$ For this reason we obtained a mean $\mathrm{MVC}$ and standard deviation from ten baseline assessments (daily recordings for 5 days and five recordings over 24 hours) for each individual muscle 


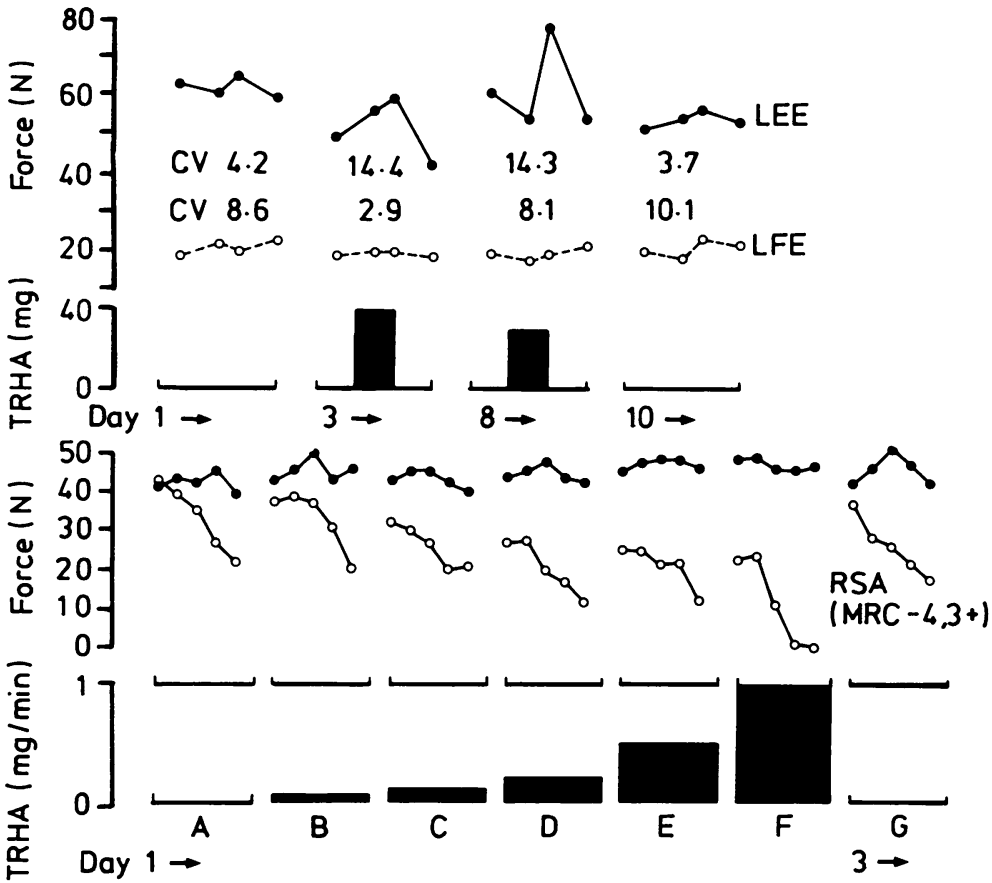

Fig 1 Dynamometry. Top: MVC recorded four times each day. Reproducible increase in left elbow' extension ( $L E E$ ) but not in left finger extension ( $L F E$ ) with $R X 77368$ (days 3 and 8). Note increase in coefficient of variation (CV) for LEE with marked random fluctuation of first MVC each day (Male, 71 years, PMA). Bottom: force of five attempts in quick succession at half hour intervals before and during infusion ( $A B \ldots F$, day 1 ) and two days later $(G) . M V C$ (first or second point in each curve) decreases with no change in fatigability (slope of each curve) in right shoulder abduction ( $R S A$, open circles). There is no change in force in right elbow extension (upper traces). (Female, 50 years, PMA). TRHA $=$ RX77368. Force in Newtons.

Table 1 Respiration

\begin{tabular}{|c|c|c|c|c|c|}
\hline & Time & $\begin{array}{l}\text { Means } \\
R x\end{array}$ & $S$ & $\begin{array}{l}\text { Mean change } \\
\pm S E(R X-S)\end{array}$ & $\begin{array}{l}\% \text { change } \dagger \\
\text { Mean } \pm S E\end{array}$ \\
\hline $\begin{array}{l}\text { MEP } \\
(p=0.04) \\
M I P \\
(p=0.03) \\
M I P \\
(p=0.02) \\
M I P \ddagger \\
(p=0.05) \\
P F \\
(p=0.03) \\
\text { VC } \\
(p=0.04) \\
\text { VC }+ \\
(p=0.02)\end{array}$ & $\begin{array}{l}2 \\
1 \\
2 \\
2 \\
2 \\
2 \\
2\end{array}$ & $\begin{array}{c}7.92 \\
(20) \\
-2.52 \\
(20) \\
1.80 \\
(20) \\
-2.62 \\
(11) \\
25.2 \\
(16) \\
0.47 \\
(16) \\
0.38 \\
(10)\end{array}$ & $\begin{array}{c}1.08 \\
(20) \\
-11.16 \\
(20) \\
-8.28 \\
(20) \\
-13.09 \\
(11) \\
-15.9 \\
(16) \\
0.20 \\
(16) \\
0.05 \\
(10)\end{array}$ & $\begin{array}{l}6.84 \mathrm{~g} / \mathrm{cm}^{2} \\
\pm 3.35 \\
\pm .64 \mathrm{~g} / \mathrm{cm}^{2} \\
\pm 3.26 \\
10.08 \mathrm{~g} / \mathrm{cm}^{2} \\
\pm 3.66 \\
10.47 \mathrm{~g} / \mathrm{cm}^{2} \\
\pm 5.80 \\
41.21 / \mathrm{min} \\
\pm 16.9 \\
0.271 \\
\pm 0.12 \\
0.331 \\
\pm 0.13\end{array}$ & $\begin{array}{r}13.4 \pm 5.36 \\
9.0 \pm 5.76 \\
14.3 \pm 5.32 \\
19.1 \pm 8.98 \\
8.6 \pm 4.72 \\
10.6 \pm 4.86 \\
15.9 \pm 6.94\end{array}$ \\
\hline
\end{tabular}

*Differences from preinfusion, then differences from similar measurements during 24 hour baseline.

tMean change (RX-S) expressed as percentage of mean 24 hour baseline.

†Bulbar syndrome. Time: hours from beginning of infusion. ( ) numbers of patients. Statistics: split plot ANOVA (RX77368 versus saline). MEP and MIP, maximal expiratory and inspiratory pressure; PF, peak flow; VC, vital capacity. 


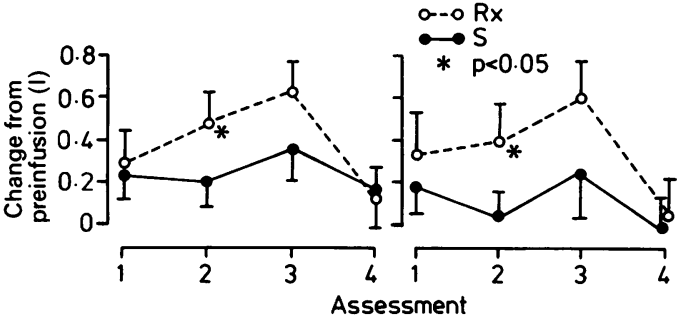

Fig 2 Effect on vital capacity. Change in mean vital capacity $\pm S E$ from preinfusion values at $1,2,6$, and 24 hours after beginning of infusions of $R X 77368$ and Saline relative to similar measurements during 24 hour baseline $(0$ baseline). Left: all measurements $(n=16)$. Right: bulbar subset $(n=10) .{ }^{*}$ Indicates significant difference between drug and placebo (ANOVA).

group in each patient. Recordings during and after each infusion were classified as increase or decrease in force if their value was above or below two standard deviations from both the mean baseline MVC and the pre-infusion MVC. To allow comparisons between muscles with large differences in strength, MVCs during and after infusion were expressed as a proportion of each (saline or drug) preinfusion MVC and compared at each assessment using a Wilcoxon Matched-Pairs Signed-Ranks test (fig 4). Increase/decrease in force as summarised in table 2 was compared by muscle group using a chi-squared test with continuity correction and by the patient using a Fisher's exact chi-squared test with order of infusion taken into account. A further analysis by total number of muscles tested was carried out using McNemar's chi-squared test with continuity correction. For respiratory and neurophysiological parameters, Norris scale, bulbar function and phonemic analysis, the response in each of the treatment periods was expressed as changes from the baseline level, that is the run-in period. Analysis of responses for the various parameters recorded was carried out using a split-plot type analysis of variance with treatment period and treatment order effects or similar non parametric tests, such as the Mann Whitney U-test. The methodology in evaluating the above effects is described by Hills and Armitage. ${ }^{38}$ Where evidence of a treatment order effect was shown, the treatment comparison was based on response in the first treatment period only.

Endocrine data were analysed with Duncan's one-way analysis of variance, except for GH, which because of nonhomogeneous variances was analysed by calculating the area under the curve (AUC) and comparing treatment with placebo using the Mann-Whitney U test. AUC was calculated using the formula $t(1 / 2 a+b+c \ldots+m+1 / 2 n)$ where $t$ is the fixed time interval, and $a$ to $n$ are the responses.

\section{Results}

A. NEUROLOGICAL FINDINGS

Pilot study

Apart from minor headache, no side effects were seen in the two normal volunteers. Four patients with

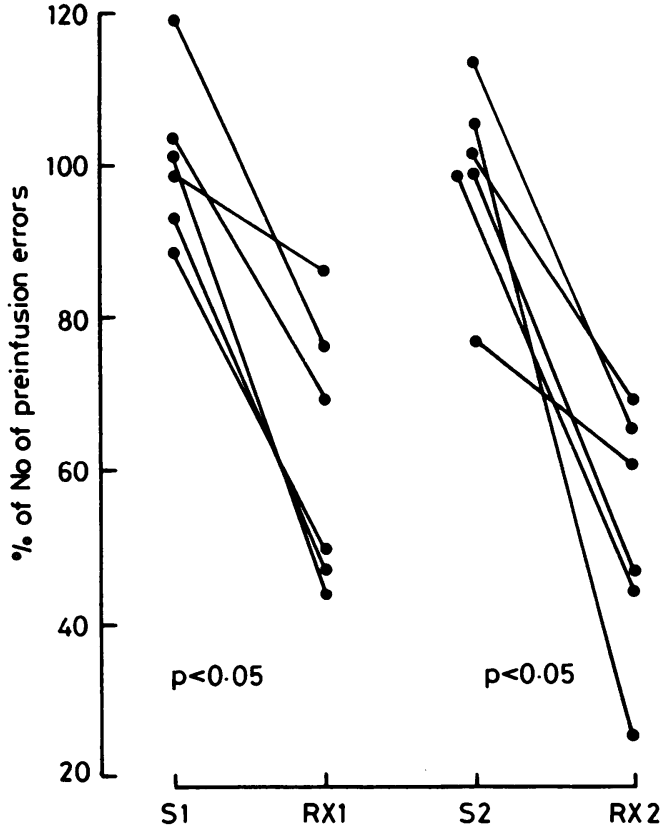

Fig 3 Effect on speech. Percentage of total number of

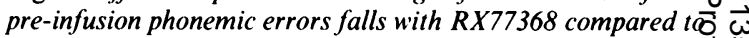
saline at end of infusion $\left(S_{1}\right.$ and $\left.R X I\right)$ and 4 hours after it $\overrightarrow{\mathbb{D}}$ $\left(S_{2}\right.$ and $\left.R X 2\right)$. Wilcoxon Signed-Ranks Matched-Pairs Test $\frac{O}{\mathbb{D}}$ 응 $p<0.05$ (no evidence of treatment order or period effects). Median absolute number of preinfusion errors was 174 for saline (range 81-260) and 169 for drug (range 84-261).

motor neuron disease reported subjective improve ment, starting at the end of the infusion and lasting upr to 72 hours, but in one there was a 5 hour latency. Either stronger arms or legs were described. Change in force was apparent to the examiner in all patients. Out of 47 muscles tested with a dynamometer, improvement was seen in nine muscle groups in five patients and deterioration in five muscle groups in three patients (fig 1). Four muscles in three patients too weak to be tested wth a dynamometer showed increase in MRC ratings. In one, biceps increased from 2 to 3 in the MRC scale for 48 hours after infusion. There was no detectable effect on muscle fatigability (fig 1). The effect on muscle force was also observed in a hypothyroid patient whose thyroid hormones did not change with the infusion. The change in muscle force did not lead to striking changes in functional capacity. Increase in fasciculations was seen in four patients. No change in tone, deep tendon reflexes nor plantar responses was observed.

Controlled study

Twenty five patients completed the study. One refused the second infusion after noting a beneficial 


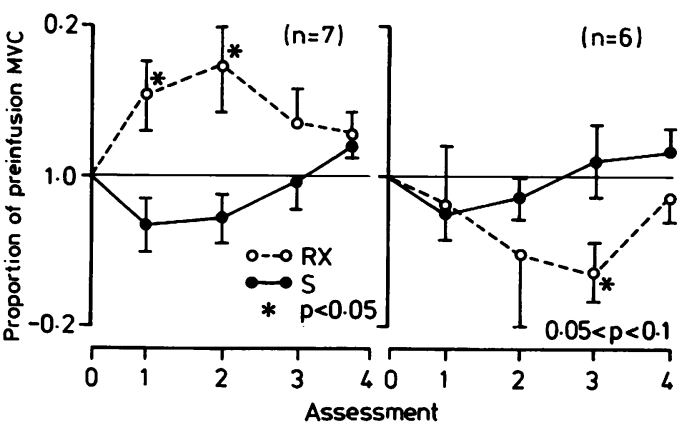

Fig 4 Effect on muscle force. Mean $M V C \pm S E$ (bars) in right biceps expressed as proportion of pre-infusion $M V C$ at 1, 2, 6 and 24 hours after beginning of infusions of $R X 77368$ and saline. For criteria to separate subsets with increase and decrease in force see methods. Wilcoxon Signed-Ranks Matched-Pairs Test.

effect with the first one (drug). There was no overall subjective preference for drug against placebo. However, 10 of the 13 patients with bulbar syndrome preferred RX77368 (Fisher's exact $\chi^{2}$ test, $\mathrm{p}=0.02$ ); they reported clearer speech, stronger voice and easier swallowing for up to 72 hours after infusion.

Temporary improvement in all respiratory parameters, except MIP, was seen with the drug (table 1). A small absolute fall in MIP with the drug was seen for all patients and in the bulbar subgroup, but the fall was significantly more marked with placebo. This resulted in a positive mean change in this parameter too. In the last column of table 1 the absolute difference between drug and placebo infusion has been expressed as a percentage of the mean 24 hour baseline to give an idea of the magnitude of the drug effect. For all patients, the mean $\%$ change ranged from $8.6 \%$ to $19 \cdot 1 \%$ of the mean 24 hour baseline values. In the bulbar subset mean \% improvement in vital capacity from baseline was $15.9 \%(\mathrm{SE}=6.9)$ (Table 1). Figure 2 shows the time course of changes in mean vital capacity for all patients and for the bulbar subset.

Eight of the patients with bulbar syndrome had predominantly spastic dysarthria which showed clinical improvement with RX77368 lasting up to 72 hours, but one of them did not have placebo infusion (Fisher's exact $\chi^{2}$ test, $p=0.05$ ). None of the four patients with anarthria improved. A further patient did not have dysarthria. Seven dysarthric patients had phonemic analysis. A marked reduction in the total number of phonemic errors with RX77368 in each of the six patients who had both drug and placebo infusions is shown in fig 3 .

In the bulbar subset there was evidence of significant improvement in total range of tongue movements at the end of drug infusion (MannWhitney U Test, $p=0.04$ ) and of swallowing 4 hours after drug infusion (Mann-Whitney $U$ Test, $p=$ 0.05). Palatal movement (repetitive elevation) was worse with the drug 4 hours after infusion (MannWhitney U Test, $p=0.05$ ).

Fasciculations increased about 1 hour into the drug

Table 2 Dynamometry. Analysis of force ( $\chi^{2}$ test with continuity correction or Fisher's exact $\chi^{2}$ where appropriate)

\begin{tabular}{|c|c|c|c|c|}
\hline $\begin{array}{l}\text { I By total number of muscles } \\
\text { †force } \\
\text { Iforce } \\
\text { No change } \\
\text { Totals }\end{array}$ & $\begin{array}{l}\text { RX } \\
80(21 \%) \\
76(20 \%) \\
225(59 \%) \\
381\end{array}$ & $\begin{array}{l}S_{52}(14 \%) \\
39(10 \%) \\
290(76 \%) \\
381\end{array}$ & & $\begin{array}{l}\text { Prob } \\
\mathbf{0 . 0 2} \\
\mathbf{0 . 0 0 5} \\
\mathbf{0 . 0 0 5}\end{array}$ \\
\hline \multirow[t]{2}{*}{$\begin{array}{l}\text { II By muscle group }(n=21) \\
\text { (a) Between groups } \\
\text { fforce } \\
\text { Iforce } \\
\text { (b) Within groups } \\
\text { fforce }>\text { |force } \\
\text { lforce }>\text { fforce } \\
\text { †force }=\text { |force }\end{array}$} & $\begin{array}{l}\mathrm{RX}>\mathrm{S} \\
15 \\
15 \\
\mathrm{RX} \\
13 \\
6 \\
2\end{array}$ & $\begin{array}{l}S_{3}>\mathrm{RX} \\
3 \\
3 \\
\mathrm{~S}^{8} \\
5 \\
8\end{array}$ & $\begin{array}{l}\mathbf{R X}=\mathbf{S} \\
\mathbf{3} \\
\mathbf{3}\end{array}$ & $\begin{array}{l}\text { Prob } \\
0.01 \\
0.01\end{array}$ \\
\hline & NS & NS & & \\
\hline $\begin{array}{l}\text { III By patient }(n=25) \\
\text { (a) Between groups } \\
\text { Change in force } \\
\text { †force } \\
\text { Iforce } \\
\text { (b) Within groups } \\
\text { †force }>\text { ।force } \\
\text { |force }>\text { †force } \\
\text { †force }=\text { |force }\end{array}$ & $\begin{array}{l}\text { RX }>\text { S } \\
17 \\
14 \\
16 \\
\text { RX } \\
9 \\
11 \\
5\end{array}$ & $\begin{array}{l}\mathrm{S}>\mathrm{RX} \\
2 \\
6 \\
5 \\
\mathrm{~S} \\
10 \\
6 \\
9\end{array}$ & $\begin{array}{l}\mathbf{R X}=S \\
6 \\
5 \\
4\end{array}$ & $\begin{array}{l}\text { Prob } \\
0.001 \\
0.17 \\
0.03\end{array}$ \\
\hline & NS & NS & & \\
\hline
\end{tabular}

RX = RX77368; S = saline; see text. 
infusion in 18 patients (Fisher's exact $\chi^{2}$ test, $\mathrm{p}<$ $0.001)$ and this effect lasted several hours. In one patient increase in fasciculations was recorded for the placebo infusion.

Spasticity decreased in six out of 13 patients who had it following drug infusion compared with no decrease following placebo (Fisher's exact $\chi^{2}$ test, $p$ $=0.03$ ) In one spasticity increased. Of nine patients with normal tone one showed increase and eight no change with the drug. No change was seen in four hypotonic patients.

No change was detected in deep tendon reflexes or plantar responses.

The main results of analysis of force are summarised in table 2 . The total number of muscles with increase and decrease in force was significantly higher with drug, and for those showing no change was significantly higher with placebo. When expressing the total number of muscles with change in force as a percentage of the number of muscles tested in each patient the mean percentage of muscles with increase in force was 19.7 for the drug and 13.2 for placebo (split-plot ANOVA, $\mathrm{p}=0.07$ ). The mean percentage of muscles with decrease in force was 20.6 for the drug and 10 for placebo (split-plot ANOVA, $p=0.004$ ). The mean number of muscles increasing in force per patient was $3 \cdot 2$ for drug and $2 \cdot 1$ for placebo (split-plot ANOVA, $p=0.06$ ). The mean number of muscles decreasing in force was 3.0 for drug and 1.6 for placebo (split-plot ANOVA, $p=0.003$ ).

Analysis by muscle group shows that for the majority (15) of the 21 muscle groups tested increase and decrease in force was seen in more patients following drug than following placebo infusion (between treatment comparison). A within treatment comparison showed no real trend in respect of the direction of the change in force over the muscle groups after either drug or placebo treatment (table 2).

Analysis by patient showed that in a greater proportion of patients more muscles changed in force with the drug than with placebo. The number of patients showing more muscles increasing and decreasing in force with drug than with placebo is close (14 and 16 respectively, table 2 ) as is the number of patients showing more muscles increasing and decreasing in force with placebo than with drug (six and five respectively, table 2). Differences of over four muscles changing in force between drug and placebo infusion were only seen in favour of drug, in four out of the fourteen patients for increase in force and in two out of the sixteen patients for decrease in force. A within treatment comparison showed no real trend in respect of the direction of change in force for the patients in the study after either drug or placebo treatment (table 2).

The findings for change in force are exemplified for right biceps in fig 4. This muscle group was tested in $\mathrm{O}$ 22 patients, with a significant increase in MVC in seven and decrease in six patients during drug as compared with placebo infusion. The ten patients in whom criteria for change in force were not met are $\frac{\bar{\theta}}{6}$ not represented in the graph. One patient appears in 0 both graphs as she showed increase in force at 2 hours and decrease at 6 hours after infusion.

There was a minor but statistically significant reduction in Norris scale score (split-plot ANOVA, $p \stackrel{2}{<}$ $=0.034$ ) with the drug related entirely to increase in $\overrightarrow{\bar{C}}$ fasciculations.

There was no difference in timed walking between $\frac{\text { ? }}{5}$ placebo and drug.

No significant difference (split-plot ANOVA) $\frac{\widehat{\Phi}}{\widehat{D}}$ between placebo and drug was found for (1) decre- $\frac{2}{2}$ ment in amplitude of compound muscle action poten- $\omega$ tial (MAP) of ADM with repetitive stimulation of the $\overrightarrow{0}$ ulnar nerve at 1 and 2 hours after starting infusions $9 . \overrightarrow{ }$ $(n=12) ;(2)$ peak to peak amplitude of the MAP of $\vec{\omega}$ ADM measured before and at 1 hour and 2 hours after starting infusion $(n=15)$; (3) distal motor $\frac{5}{0}$ latency to $\operatorname{ADM}(n=17)$ and maximal motor nerve ir conduction velocity $(n=16)$ of the elbow-wrist segment of the ulnar nerve measured before and at the. end of infusion.

\section{B. ENDOCRINE FINDINGS \\ Pilot study}

Only three of the four patients given two infusions were evaluated. In two of the three the maximum response of TSH to RX77368 was less for the secons infusion than for the first, and the dose-response curve is shifted to the right (fig 5 Panel D). This is despite the fact that they received a larger total dose. during the second infusion than the first. In the third patient, RX77368 was infused at $20 \mathrm{mg} /$ hour (total dose $40 \mathrm{mg}$ ) first, and at $15 \mathrm{mg} /$ hour (total dose $\frac{\partial}{0}$ $30 \mathrm{mg}$ ) on the second occasion. Despite such a modest reduction in dosage, there was a considerable reduc- $\mathbb{D}$ tion in the TSH response to the second infusion (fig $5 \stackrel{2}{\Rightarrow}$ Panel C). One patient had primary hypothyroidism and his markedly elevated levels of TSH did not respond to RX77368. His normal prolactin levels were elevated after 30 minutes, then subsided during the rest of the infusion (fig 5 Panels A and B). Thyroxine remained undetectable throughout the infusion.

\section{Controlled study}

One patient with treated hypothyroidism was excluded from analysis of thyroid function. In the remaining subjects TSH (fig 6) rises progressively dur- 윽 ing the infusion. After the infusion, levels decline over $\frac{D}{2}$ 12 hours.

Prolactin (fig 6) levels peak after 30 minutes $N$ infusion, thereafter falling to a plateau at 90 minutes. 

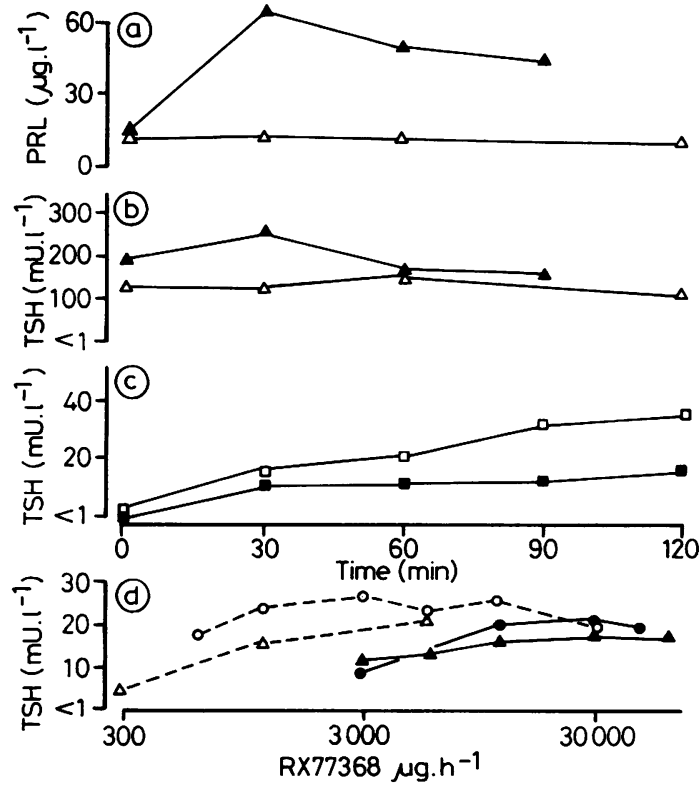

Fig 5 Endocrine responses. Pilot study. Panels $a$ and $b: a$ previously untreated hypothyroid patient with motor neuron disease was infused with $R X 7736810000 \mu \mathrm{g} / \mathrm{hr}(\Delta)$ and saline $(\triangle)$ one week apart. Panel c: a patient was given two infusions of $R X 77368$ four days apart. The first infusion rate was $20000 \mu \mathrm{g} / \mathrm{hr}(\square)$, the second rate was $15000 \mu \mathrm{g} / \mathrm{hr}$

(ם). Panel d: two patients were each infused with $R X 77368$ on two separate occasions, four days apart. Patient 1 , first infusion, (O) received a total dose of $25 \cdot 2 \mathrm{mg}$, second infusion, (O) total dose of $52.5 \mathrm{mg}$. Patient 2, first infusion, $(\Delta)$ received a total dose of $8.46 \mathrm{mg}$, second infusion, $(\Delta)$ total dose $59 \mathrm{mg}$.

After the infusion, levels rapidly decline to normal within 6 hours.

RX77368 stimulates the integrated secretion of GH (p < 0.05) (fig 7). The maximum level of GH was 10.1 $\pm 1.4 \mu \mathrm{g} / \mathrm{l}$ at 120 minutes after the start of the infusion. Cortisol (fig 7) was not significantly affected by RX77368. The expected diurnal decline in cortisol did not occur in either the RX77368 or placebo group.

Thyroxine (fig 6) levels rose within 60 minutes of the start of the infusion, and the increase was significant by 120 minutes. Levels rose even higher 6 hours after the end of the infusion and did not return to normal until 72 hours after the end of the infusion. $T_{3}$ levels rose earlier than $T_{4}$, and the increase was significant by 90 minutes. $T_{3}$ levels returned to normal within 48 hours.

Side effects were clinically important in 13 patients $(50 \%)$. They included cold and warm sensations, nausea, shivering, paraesthesia and dysaesthesia, vomiting, irritability, sweating, tiredness, nasal secretion, dry mouth, headache, motor agitation, itchy throat and cough. Transient minor elevation in blood pressure was seen in one elderly patient with bulbar syndrome. They usually cleared within 12 hours. During the pilot study vaginal sensations, palpitations, hiccup, insomnia, abnormal taste, urgency of micturition, flatulence and visual obscuration were also seen.

Monitoring of skin temperature, blood pressure, electrocardiogram and haematological renal and liver function laboratory parameters showed no toxic side effects in both the pilot and controlled studies.

\section{Discussion}

TRH, a tripeptide found in the hypothalamus, was originally described for its effects on anterior pituitary function. ${ }^{39}$ However, about two thirds of total TRH are found in extrahypothalamic sites including cerebral cortex, hippocampus, brain stem and spinal $\operatorname{cord}^{\mathbf{4 0}}$ and it is believed to be a neurotransmitter or neuromodulator. ${ }^{41}$ The role of TRH in the spinal cord is unknown but it is found in high concentrations in the anterior horns, close to the anterior horn cells. ${ }^{42}$ TRH receptors have been described in human spinal cord ${ }^{43}$ and their density is diminished and distribution altered in motor neuron disease. ${ }^{44}$

Motor neuron disease is associated with spinal cord depletion of TRH content relative to wet weight ${ }^{4546}$ but not relative to protein content. ${ }^{45}$ TRH and analogues may accelerate recovery from spinal trauma in cats $^{4748}$ and have excitatory effects on rat $^{4950}$ and cat $^{51}$ motorneurons.

Engel et al gave very large doses of TRH in an open study to patients with motor neuron disease, and observed a temporary increase in power and reduction in spasticity. ${ }^{4}$ Considerable side effects were seen, notably nausea and vomiting. Temporary beneficial effects of TRH in spinocerebellar degenerations were described by Sobue et al. ${ }^{52} 53$

We have infused a TRH analogue, Lpyroglutamyl-L-hystidyl-L-3,3 dimethyl prolineamide (RX77368), $0.3 \mathrm{mg} / \mathrm{kg} \mathrm{IV}$ over 2 hours, and have produced temporary improvement in patients with motor neuron disease with bulbar syndrome, both subjectively and in various tests of bulbar function. In addition, there is increase in fasciculations, and a statistically significant reduction in spasticity and change in muscle force with the drug. Fifty percent of the patients did not have clinically significant side effects.

There are many methodological problems in a trial of this nature. Diagnostic criteria have been stringent. To avoid interobserver variation one experienced observer was used for all neurological and respiratory assessments. Another observer performed all other 


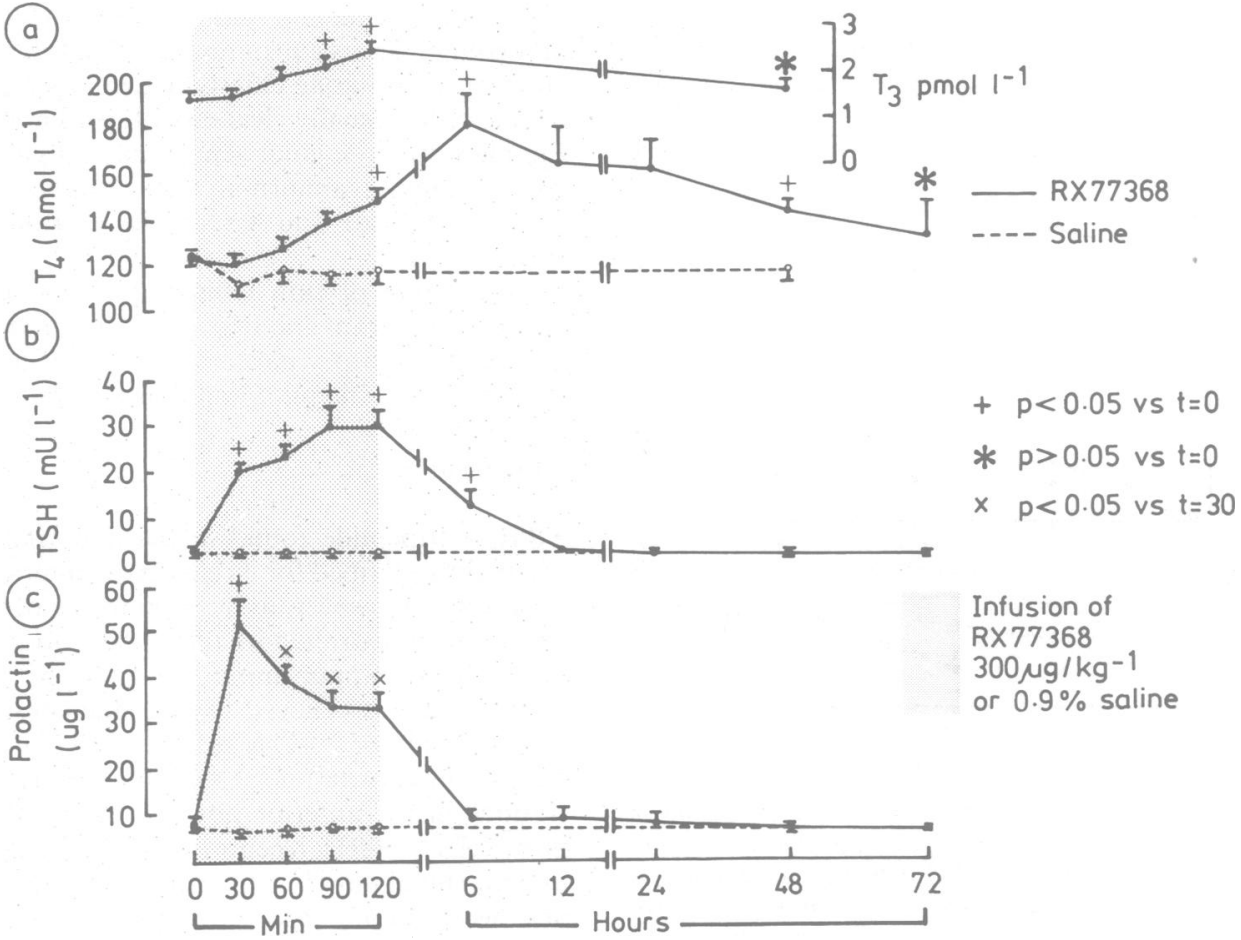

Fig 6 Endocrine responses to a $2 \mathrm{~h}$ infusion of $R X 77368$. Statistical analysis was performed using Duncan's 1 -way analysis of variance. $P$ values of less than 0.05 are considered significant.
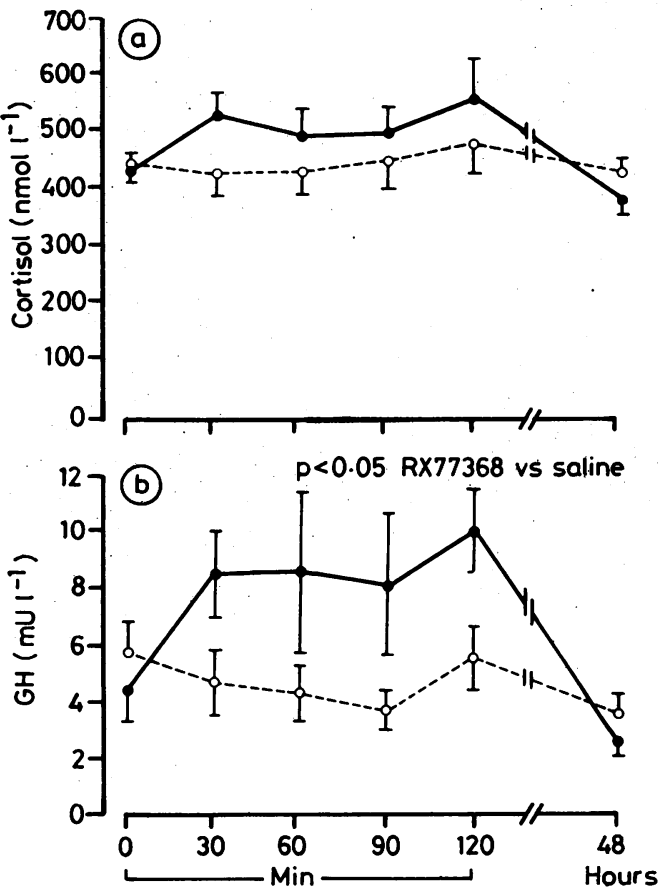

Fig 7 Cortisol and growth hormone response to infusions of $R X 77368(\bigcirc)$ and saline $(\bigcirc)$. The infusions started at $t=0$ and finished at $t=120$. Statistical analysis was performed by calculating the area under the curve from $t=0$ to 120 minutes and comparing the $R X 77368$ infusion with saline using the Mann-Whitney $U$ test. $P$ values of less than 0.05 are considered significant. 
bulbar function measurements including scoring of tape recordings of speech. Variations in bulbar involvement, degree of spasticity, pyramidal weakness and patchy lower motor neuron weakness result in marked variations in clinical picture and functional capacity from patient to patient. There are also fluctuations in performance in each patient over time. The test situation, with 2 hour infusions and a number of measurements being performed, is likely to introduce further variation. Attempts to control for these factors included random cross-over design and appropriate baseline measurements in each patient, against which both drug and saline infusions were compared. The infusions were separated by 7 days, an interval deemed adequate from other data from our group and treatment $\times$ period interaction was considered in the statistical analysis. ${ }^{38}$ The double blind nature of the trial may be questioned because of the side effects of the drug. However in $50 \%$ of the patients they were not clinically significant and a few patients had side effects with placebo (nausea, vomiting). Measurements that showed the most clear drug effect (speech, respiration) are unlikely to have had observer bias (see methods).

The most striking beneficial effect of RX77368 was improvement in predominantly spastic dysarthria both in clarity and volume, as described for native TRH (fig 3). ${ }^{4}$ The power of the trial to detect the mean $41 \%$ improvement seen with a mean standard deviation of the difference of $20 \%$ was greater than 0.9. Subjective improvement in speech in seven out of 12 patients given native TRH by Caroscio et al $^{15}$ was not confirmed by analysis of their tape recordings. The cross-over intervals in this trial were short, 72 hours between drug and placebo and 96 hours between iv and sc routes. Mitsumoto et al $^{14}$ and Brooke et al ${ }^{16}$ only measured the time required to repeat three syllables ten times and repetition of a standard sentence respectively. The effect lasted up to 72 hours in our patients and was reported for up to 48 hours by Caroscio's patients. ${ }^{15}$ The effects on respiratory parameters (table 1, fig 2) might also be useful. Improvement in vital capacity with native TRH has been noted by some ${ }^{4810}$ but not by others. ${ }^{141516}$ Transient improvements in range of tongue movements and swallowing were noted both subjectively and objectively in patients with bulbar syndrome with the methods used here. Palatal movement paradoxically showed deterioration after infusion. Improvement in force of tongue elevation and in facial muscles has been reported for native TRH. ${ }^{10}$

Data on muscle force show that a similar number of muscles, muscle groups and patients have increase as have decrease in force with the drug at the dose used (table 2, fig 4). The effect on force was modest, rarely extended beyond 6 hours after infusion and was seldom clinically useful. Only in four out of 14 patients $(29 \%)$ who had more muscles that increased in force with drug than with placebo was the difference of four or more muscles. Increase in fasciculations, lack of an effect on fatigability (fig 1 ) and lack of decrement of the MAP of ADM argue against an action of the drug on the neuromuscular junction and are consistent with a direct or indirect action on anterior horn cells. Lack of effect on maximal motor nerve conduction velocity and distal motor latency are against an action on distal fastest conducting motor fibres. A complex effect at various levels, including blood vessels and muscle, cannot be ruled out. In some muscles we observed both increase and decrease in force with the drug, in any order. The direction of change in force in any muscle in an individual patient could not be predicted at the dose used, that is did not differ from direction of change in force with placebo (table 2 , within group analysis). The "autorefractory state" described for native TRH ${ }^{54}$ with initial increase in force and later decrease in force with subsequent doses was not observed by us. Decrease in force was seen in some muscles with small doses and further decrease with subsequent doses (fig 1). It is uncertain whether differences in methodology or in the actions of TRH and RX77368 account for this discrepancy. Faden et al ${ }^{48}$ suggest that neurological recovery after spinal cord injury in cats improves with TRH and with an analogue with a substitution in the pyroglutamyl ring of the tripeptide (CG3509) but not with another analogue which has modifications to both the pyroglutamyl and prolineamide rings (MK771). Future identification of the mechanisms underlying change in force with TRH and analogues and in particular, its direction, in patients with motor neuron disease, is needed. There is no compelling reason to assume that pharmacological agents will have a similar effect on all muscle groups. The anatomical location and synaptic connectivity of anterior horn cells in lamina IX of Rexed is said to be different for proximal and distal muscles ${ }^{55}$ and the fibre type composition of different muscles varies. ${ }^{56}$

The findings on muscle force are consistent with the lack of observable difference between drug and placebo in both timed walking and Norris scale. However, several patients reported general improvement in strength and in various activities, including walking, with the drug. The distance timed was only 6 metres and the Norris scale may not be sensitive enough to detect this subjective impression. ${ }^{57}$ Further refinement of techniques for assessing functional status in motor neuron disease seems desirable.

High doses of TRH or its analogues had not been given to humans before their use in motor neuron 
disease. Monitoring the endocrine responses, both as a biological marker of TRH activity and to assess the potential endocrine side effects is important.

TRH is used for the assessment of pituitary-thyroid function as a bolus dose of up to $500 \mu \mathrm{g}$. We have given dosages probably up to 800 times larger on an equipotent dosage basis. Most of the previous literature relating to the actions of TRH on the endocrine system is not therefore comparable. Certain similarities, however, do exist. Lower dose infusions of TRH have shown a similar PRL response to ours, ${ }^{5859}$ whereas very low dose infusions have shown only a small, transient increase in PRL. ${ }^{60}$ The TSH responses seen in these other studies were also similar. The mechanisms responsible for the pattern of prolactin output we have seen is not clear. It may be related to prolactin inhibiting its own output at the level of the pituitary ${ }^{61}$ or to changes in hypothalamic dopamine output.

Our pilot study suggests that there is a down regulation in the biological response to a second infusion of RX77368, despite a return to basal concentrations of $T_{4}$ and $T_{3}$. It is unclear whether such down regulation is mediated via peripheral thyroid hormones, ${ }^{62}{ }^{63} \mathrm{TSH}^{60}$ or by the analogue itself. ${ }^{62}$ TRH receptor down regulation occurs at various sites within the CNS, ${ }^{65}$ but studies have not been performed on spinal TRH receptors. The endocrine effects of long term infusions of TRH or its analogues are difficult to predict. In the existing literature, TSH concentrations remain elevated in ewes ${ }^{66}$ but return to normal in monkeys ${ }^{67}$ and lambs. ${ }^{68}$ Peripheral thyroid hormones remained elevated throughout these studies.

RX77368 stimulates the release of GH. Whilst TRH is not commonly recognised as a GH releasing factor, in some clinical situations, such as acromegaly ${ }^{69}$ and "normal variant tall stature", 7071 GH releasing activity is seen. Since RX77368 has no effect on cortisol release it is unlikely that its effects on the release of other hormones is mediated via a stress response. In the recovery phase, after termination of the infusion of $R X 77368, T_{3}$ concentrations return to normal more rapidly than $T_{4}$. Since most $T_{3}$ is formed by peripheral monodeiodination of $T_{4}$, it would appear that this conversion is inhibited in patients after the administration of RX77368. This would minimise the potential of this analogue to cause thyrotoxicosis. This potential hazard could be controlled with anti-thyroid drugs. If the spinal TRH receptors are shown to be significantly different from those on the pituitary, spinally active analogues may also be designed which do not affect TSH secretion. ${ }^{72}$

It is unlikely that the changes in neurological parameters are the result of changes in peripheral thyroid hormones. (1) Changes in muscle force and bulbar function parameters preceded significant changes in $T_{3}$ and $T_{4}$. (2) Neurological changes were observed in a patient with primary hypothyroidism whose thyroid hormones did not change during drug infusion. (3) Neuropharmacological effects of TRH and analogues in experimental animals are not mediated via peripheral thyroid hormones. ${ }^{517374}$ (4) The effects of thyroxine at cellular level are not seen for several hours. ${ }^{75}$

This trial was designed to establish the acute effects of the analogue at a dose judged from the pilot study to maximise neurological action with an acceptable degree of clinical side effects. Prolonged therapy should be explored to establish whether the improvements seen can be maintained. Although others have failed to show a change in the course of the illness so far with native TRH ${ }^{141676}$ any symptomatic effect that might improve quality of life would be important. In addition, any possible effect of this and other TRH analogues on the course of the disease is worth studying.

We are grateful to the following neurologists for referring patients to this trial: $\mathbf{R}$ Abrahams, J Durston, M Espir, B Gibberd, R Greenwood, P Harvey, R Hughes, J Jestico, J Phemister, E Reynolds, D Thomas, G Stern, and S Wilson. Dr RCO Hoare is a member of the Statistical Division, Reckit and Colman Pharmaceutical Division.

DJAE is an MRC Training Fellow.

This work was supported by grants from the Motor Neuron Disease Association of Great Britain, the NW Thames Regional Health Authority and the Special Trustees of Westminster and Roehampton Hospitals.

\section{References}

1 Kurtzke JF. Epidemiology of amyotrophic lateral sclerosis. $A d$ Neurol 1982;36:281-302.

2 Acheson ED. In: Multiple Sclerosis. A Reappraisal. London Churchill Livingstone, 1972:6.

3 Guiloff RJ, McGregor B, Thompson E, et al. Motor neurone disease with elevated cerebrospinal fluid protein. $J$ Neurol Neurosurg Psychiatry 1980;43:390-6.

4 Engel WK, Siddique T, Nicoloff JT. Effect on weakness and spasticity in amyotrophic lateral sclerosis of thyrotrophin releasing hormone. Lancet 1983;2:73-5.

5 Engel WK, van den Bergh P, Askanas V. Subcutaneous thyrotrophin releasing hormone seems ready for wider trials in treating lower motor neurone produced weakness and spasticity. Ann Neurol 1984;16:109-10.

6 Jerusalem F, Fresmann J. Comparison of treatment trials in ALS between thyrotrophin releasing hormone (TRH) and TRH-derivate orotyl-L-histidyl-L-prolineamide. $J$ Neurol 1985;suppl 232:35.

7 Maruyama S, Kobayashi I, Yamane K, et al. Clinical and neurophysiological effects of TRH on ALS. J Neurol 1985;suppl 232:35. 
8 Konishi T, Sakakibana T, Konayaga M, et al. The effect of TRH on respiratory function in ALS. $J$ Neurol 1985;suppl 232:35.

9 Brooks BR, Sufit RL, Beaulieu DA, et al. Intravenous $(10 \mathrm{mg} / \mathrm{kg}$ ) thyrotrophin releasing hormone (TRH) administration in amyotrophic lateral sclerosis (ALS): decreased loss of muscle strength in TRH-treated patients during parallel placebo controlled pilot study. J Neurol 1985;suppl 232:264.

10 Gracco VL, Caliguri M, Abbs JH, et al. Placebo controlled computerized dynametric measurements of bulbar and somatic muscle strength increased in patients with amyotrophic lateral sclerosis following intravenous infusion of $10 \mathrm{mg} / \mathrm{kg}$ thyrotrophin releasing hormone. Ann Neurol 1984;16:110.

11 Sufit R, Beaulieu D, Sanguq M, et al. Placebo controlled quantitative measurements of neuromuscular function following intravenous infusion of $10 \mathrm{mg} / \mathrm{kg}$ thyrotrophin releasing hormone in 16 patients with amyotrophic lateral sclerosis. Ann Neurol 1984;16:110.

12 Yamane K, Osawa M, Kobashaki J, et al. Therapeutic trial of TRH (thyrotrophin releasing hormone) in amyotrophic latera sclerosis. Prog Med (Japan) 1984;128:235-6.

13 Imoto K, Saida K, Iwamura K, et al. Amyotrophic lateral sclerosis: a double blind crossover trial of thyrotrophin releasing hormone. J Neurol Neurosurg Psychiatry 1984;47:1332-4.

14 Mitsumoto H, Salagado ED, Negroski D, et al. Amyotrophic lateral sclerosis: effects of acute intravenous and chronic subcutaneous administration of thyrotrophin-releasing hormone in controlled trials. Neurology 1986;36:152-9.

15 Caroscio JT, Cohen JA, Zawodniak J, et al. A double-blind placebo controlled trial of TRH in amyotrophic lateral sclerosis. Neurology 1986;36:141-5.

16 Brooke MH, Florence JM, Heller SL, et al. Controlled trial of thyrotrophin releasing hormone in amyotrophic lateral sclerosis. Neurol 1986;36:146-51.

17 Morgan BA, Bower JD, Dettmar PW, et al. Novel TRH analogs with increased neuropharmacological activity. In: Gross E, Meienhofer J, eds. Peptides: Structure and Biological Function. Proc 6th American Peptide Symposium. Rockford, Illinois: Pierce Chemical Co, 1979:909-12.

18 Brewster D, Dettmar PW, Metcalf G. Biologically stable analogues of TRH with increase neuropharmacological potency. Neuropharmacology 1981;20:497-503.

19 Brewster D. Species variations in TRH inactivation. Advantages of stable analogues. In: Griffiths EC, Bennett GW, eds. Thyrotrophin Releasing Hormone. New York: Raven Press, 1983:109-18.

20 Metcalf G, Dettmar PW. Is thyrotrophin releasing hormone an endogenous ergotropic substance in the brain? Lancet 1981;i:586-9.

21 Metcalf G, Dettmar PW, Fortune D, et al. Neuropharmacological evaluation of RX77368-a stabilised analogue of thyrotrophin-releasing hormone (TRH). Regulatory Peptides 1982;3:193-206.

22 Metcalf G, Dettmar PW, Lynn AG, et al. Thyrotrophin-releasing hormone (TRH) analogues show enhanced CNS selectivity because of increased biological stability. Regulatory Peptides 1981;2:277-84.

23 Griffiths EC, Baris C, Visser TJ, et al. Thyrotrophin-releasing hormone inactivation by human post mortem brain. Regulatory Peptides 1985;10:145-55.

24 Clarke KA, Stirk G. Motor neurone excitability after administration of a thyrotrophin releasing hormone analogue. Br J Pharmacol 1983;80:561-5.

25 Clarke KA, Parker AJ, Stirk G. Motor neurone excitability during antidromically evoked inhibition after administration of a thyrotrophin releasing hormone (TRH) analogue. Neuropeptides 1984;4:403-11.

26 Guiloff RJ, Nagendran K, Eckland D, et al. Effects of a TRH analogue (RX77368) on some clinical manifestations of motor neurone disease. Report of a pilot study. Clin Sci 1985;68(suppl 11):47-8.
27 Eckland D, Lightman S, Nagendran K, et al. The effects of a thyrotrophin releasing hormone (TRH) analogue (RX77368) on the endocrine function of patients with motor neurone disease. $J$ Neurol 1985; suppl 232:36.

28 Guiloff RJ, Nagendran K, Eckland D, et al. Effects of a TRH analogue (RX77368) on some clinical manifestations of motor neurone disease. $J$ Neurol 1985; suppl 232:36.

29 Eckland D, Lightman S, Nagendran K, et al. The endocrine manifestations of high doses of a thyrotrophin releasing hormone (TRH) analogue, RX77368 in patients with motor neurone disease (MND). Clin Sci 1986;70(suppl 13): 15 .

30 Norris FH, Calanchini PR, Fallat RJ, et al. The administration of guanidine in amyotrophic lateral sclerosis. Neurology 1974;24:721-8.

31 Medical Research Council. Memorandum No 45. Aids to the Examination of the Peripheral Nervous System. London: HMSO, 1976.

32 Wiles CM, Karni Y. The measurement of muscle strength in patients with peripheral muscular disorders. J Neurol Neurosurg Psychiatry 1983;46:1006-13.

33 Knight RJ. The Hospital Calculair. An assessment of a portable electronic spirometer. Anaesthesia 1981;36:620-3.

34 Black LF, Hyatt RE. Maximal respiratory pressures: normal values and relationship to age and sex. Am Rev Respir Dis 1969;99:696-702.

35 Black LF, Hyatt RE. Maximal static respiratory pressures in Generalized Neuromuscular Disease. Am Rev Respir Dis 1971;103:641-50.

36 Grumwell P. Clinical Phonology. London: Groom Helm Publ, 1982.

37 Tornvall G. Assessment of Physical Capabilities with special reference to the evaluation of maximal voluntary isometric muscle strength and maximal working capacity. Acta Physiol Scand 1963;58(suppl 201):5-102.

38 Hills $M$, Armitage P. The two period cross-over clinical trial. Br J Clin Pharmacol 1979;8:7-20.

39 Burgus R, Dunn TE, Desiderio D, et al. Characteristics of bovine hypothalamic hypophysiotropic TRH releasing factor. Nature 1970;336:321-5.

40 Lechan RM, Snapper SB, Jacobson S, Jackson IMD. The distribution of thyrotrophin releasing hormone (TRH) in the rhesus monkey spinal cord. Peptides 1984;5(suppl 1):185-94.

41 Jackson IMD. Thyrotrophin releasing hormone. $N$ Engl J Med 1982;306:145-55.

42 Hökfelt T, Fuxe O, Johaneson S, et al. Thyrotrophin releasing hormone (TRH) containing nerve terminals in certain brain stem nuclei and in the spinal cord. Neuro'sci Lett 1975;1:133-9.

43 Manaker S, Winokur A, Rhodes $\mathrm{CH}$, ét al. Autoradiographic localization of thyrotrophin-releasing hormone (TRH) receptors in human spinal cord. Neurology 1985;35:328-32.

44 Manaker S, Shulman LH, Winokur A, et al. Autoradiographic localization of thyrotrophin-releasing hormone receptors in amyotrophic lateral sclerosis spinal cord. Neurology 1985;35:1650-3.

45 Jackson IMD, Adelman LS, Munsat TL, et al. Amyotrophic lateral sclerosis: thyrotrophin-releasing hormone and hystidyl proline diketopiperazine in the spinal cord and cerebrospinal fluid. Neurology 1986;36:1218-23.

46 Mitsuma T, Nogimori T, Adachi K, et al. Concentrations of immunoreactive thyrotrophin-releasing hormone in spinal cord of patients with amyotrophic lateral sclerosis. $\mathrm{Am} \mathrm{J} \mathrm{Med}$ Sci 1984;287(2):34-6.

47 Faden AI, Jacobs TP, Holaday JW. Thyrotrophin releasing hormone improves neurologic recovery after spinal trauma in cats. N Engl J Med 1981;305:1063-7.

48 Faden AI, Jacobs TP. Effect of TRH analogs on neurologic recovery after experimental spinal trauma. Neurology 1985;35:1331-4.

49 Ono H, Fukuda $H$. Ventral root Depolarization and Spinal Reflex Augmentation by a TRH analogue in Rat Spinal Cord. 
Neuropharmacology 1982;21:739-44.

50 Clarke KA, Stirk G. Motorneurone excitability after adminstration of a thyrotrophin-releasing hormone analogue. Br J Pharmacol 1983;80:561-5.

51 Cooper BR, Boyer CE. Stimulant action of thyrotrophin releasing hormone on cat spinal cord. Neuropharmacology 1978; 17:153-6.

52 Sobue I, Yamamoto H, Konagaya M, et al. Effect of thyrotrophin-releasing hormone on ataxia of spinocerebellar degeneration. Lancet 1980;1:418-9.

53 Sobue I, Takayanagi T, Nakanishi T, et al. Controlled trial of thyrotrophin-releasing hormone ta in ataxia of spinocerebellar degenerations. J Neurol Sci 1983;61:235-48.

54 Engel WK, Siddique T. Transient autorefractory (AR) state of transmitter-like effect of thyrotrophin-releasing hormone (TRH) in amyotrophic lateral sclerosis (ALS): a new clinical phenomenon. Neurology 1984;34(suppl): 147.

55 Kuypers HGJM. The Anatomical Organization of the Descending Pathways and their Contributions to Motor Control Especially in Primates. In: Desmedt S, ed. New Developments in Electromyography and Clinical Neurophysiology Vol 3. Basel: Karger, 1973:38-68.

56 Johnson MA, Polgar J, Weightman D, et al. Data on the distribution of fibre types on thirty-six human muscles: an autopsy study. J Neurol Sci 1973;18:111-29.

57 Shafer SQ, Olarte MR. Methodological considerations for clinical trials in motor neurone disease. In: Rowland LP, ed. Human Motor Neurone Diseases. New York: Raven Press, 1982;36:559-66.

58 Mongioi A, Aliffi A, Vicari E, et al. Down-regulation of prolactin secretion in men during continuous thyrotrophin releasing hormone infusion: evidence for induction of pituitary desensitization by continuous TRH administration. J Clin End Metab 1983;56(5):904-7.

59 Brenner WJ, Abreu R, Stockigt JR, et al. Pituitary-Thyroid Responses to 4-hour constant infusions of Thyrotrophin Releasing Hormone in man. J Clin End Metab 1977;45(5): 981-7.

60 Spencer CA, Greenstadt MA, Wheeler WS, et al. The influence of long-term low dose thyrotrophin-releasing hormone infusions on serum thyrotrophin and prolactin concentrations in man. $J$ Clin End Metab 1980;51(4):771-5.

61 Herbert DC, Ishikawa H, Rennels EG. Evidence for the autoregulation of hormone secretion by prolactin. Endocrinology 1979;104(1):97-100.

62 Hinkle PM, Tashjian AH. Thyrotrophin releasing hormone regulates the number of its own receptors in the $\mathrm{GH}_{3}$ strain of pituitary cells in culture. Biochemistry 1975;14(17):3845-51.

63 Gershengorn MC. Bihormonal regulation of the thyrotrophin releasing hormone receptor in mouse pituitary thyrotrophic tumour cells in culture. J Clin Invest 1978;62:937-43.

64 Liu CM, Hedge GA. Factors involved in the attenuation of the
Guiloff, Eckland, Demaine, Hoare, MacRae, Lightman

TSH response to a second injection of TRH in the rat. Neuroendocrinology 1983;36:95-101.

65 Ogawa N, Mizuno S, Nukina I, et al. Chronic thyrotrophin releasing hormone (TRH) administration on TRH receptors and muscarinic cholinergic receptors in CNS. Brain Res 1983;263:348-50.

66 Klindt J, Davis SL, Ohlson DL. Plasma concentration of thyrotrophin releasing hormone, thyrotrophin, prolactin, and growth hormone during five day osmotic pump infusion of thyrotrophin releasing hormone. Endocrinology 1979;104(1): 45-9.

67 Pavasuthipaisit K, Normon RL, Ellinwood WE, et al. Different prolactin, thyrotrophin and thyroxine responses after prolonged intermittant or continuous infusions of thyrotrophin releasing hormone in Rhesus monkeys. J Clin End Metab 1983;56(3):541-8.

68 Muir LA, Wien S. Effects of thyrotrophin-releasing hormone and a thyrotrophin releasing hormone analogue on growth and selected plasma hormones in lambs. J Animal Sci 1983;57(1): 139-45.

69 Irie $\mathrm{M}$, Tsuishima $\mathrm{T}$. Increase of serum growth hormone concentration following thyrotrophin releasing hormone injection in patients with acromegaly or gigantism. J Clin End Metab 1972;35(1):97-100.

70 Blanco MG, Brion DE. Studies in constitutionally tall adolescents: somatostatin decrease associated with growth hormone increase after TRH injection. Clin Endocrinol 1984;21:459-63.

71 Evain-Brion D, Garnier P, Blanco-Garcia M, et al. Studies in constitutionally tall adolescents. II. Effects of bromocriptie on growth hormone secretion and adult height prediction. J Clin End Metab 1984;58(6): 1022-6.

72 Babichev VN, Samsonova VM, Airapetyants MG, et al. Neuroscience effects of thyroliberin and its analogues. Neuroscience Behav Physiol 1982;12(5):394-7.

73 Prange AJ, Nemeroff CB, Lipton MA. Behavioural Effects Peptides: Basic and Clinical Studies. In: Lipton MA, Di Mase cio A, Killam DF, eds. Psychopharmacology: A Generation of Progress. New York: Raven Press, 1978:441-58.

74 Sharp T, Tullock IF, Bennett GW, et al. Analeptic effects of centrally injected TRH and analogues of TRH in the pentobarbitone-anaesthetized rat. Neuropharmacology 198

75 Dillman WH, Mendecki J, Koerner D, et al. Tri户 iodothyromine-stimulated formation of poly(A)-containing nuclear RNA and mRNA in rat liver. Endocrinology 1978; 102:568-75.

76 Engel WK, Spiel RH. Prolonged at-home treatment of motor neurone disorders with self-administered subcutaneous high-dose TRH. Neurology 1985;35(suppl 1):106-7.

77 Serratrice G. Note sur l'utilisation de la TRH dans la sclerose latérale amyotrophique. Bull Acad Natle Med 1985;169: 1013-7. 